\title{
Virtual detox: Inpatient therapy for Internet addicts
}

B en Alexander began dabbling in the online role-playing game World of Warcraft during his first year of university. In the beginning, he devoted a few hours a day to the game. Midway through his first semester, however, the Iowa teenager's hobby morphed into an obsession. He would sometimes play for 17 hours in one day, which left little time for school, so he quit.

But unlike many young gamers, Alexander, now 19, eventually realized he had a problem and sought help. He enrolled in an intensive 45-day program - no computers allowed - and thus became Patient No. 1 at reSTART, a treatment facility that bills itself as the first detox centre in the United State for Internet addicts (www.netaddiction recovery.com).

"A 45-day cyber-fast is a good, long time to allow the brain to start wiring back to normal," says Hilarie Cash, a mental health counsellor and reSTART cofounder.

The six-bed facility, located on five acres of land in Fall City, Washington, opened on July 26. As of the beginning of September, Alexander was the only patient, though more requests were coming in, says Cash. The Internet addiction recovery program, which costs US $\$ 14500$, is "oriented toward launching tech-dependent youth and adults back into the real world."

It includes talk therapy, life-skills coaching, physical and nutritional education, work and home-maintenance skill-building, 12-step meetings and "high-adventure expeditions." Instead of slaying digital ogres with flaming swords, gamers feed real goats and raise chickens.

"We want to give them a positive experience of being in the real world," says Cash.

Cash has been helping people with technology-related obsessions since 1994, when she treated a man whose video game habit had cost him two jobs and a marriage. Though video games

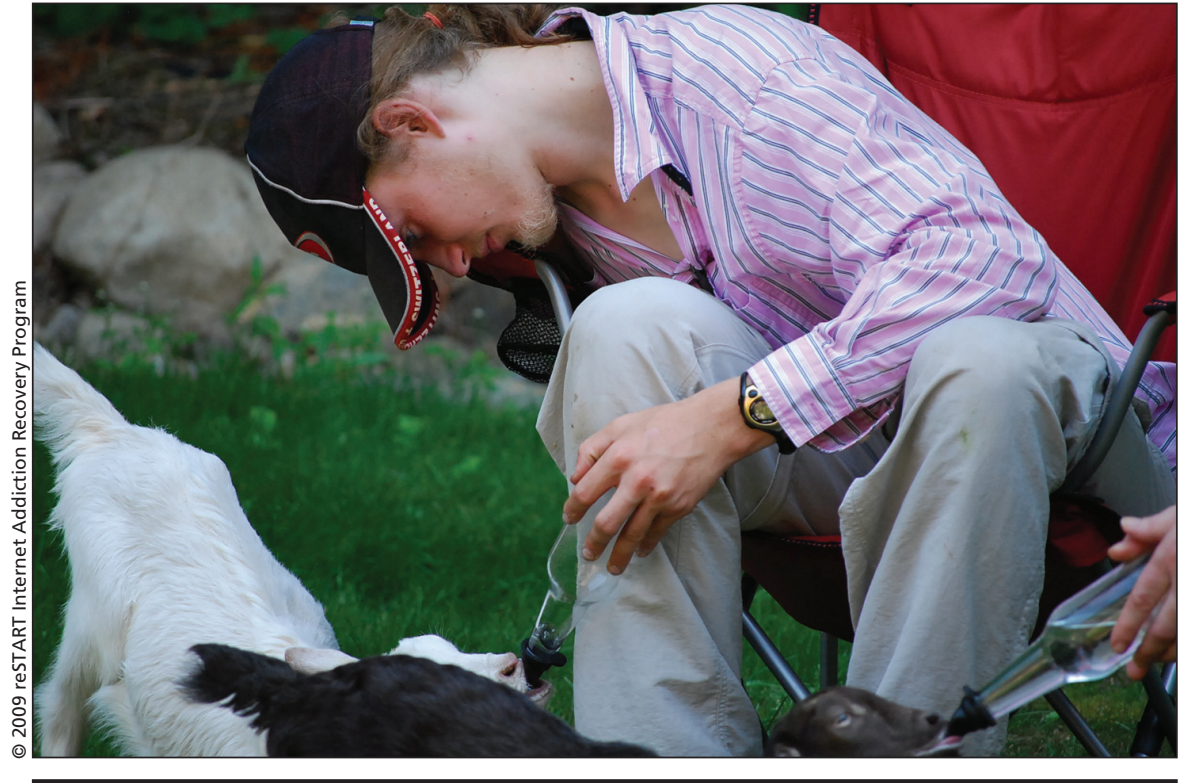

Ben Alexander, 19, plays with a goat as part of a therapeutic program offered by the first detox centre for Internet addicts in the United States.

are as popular as ever, now many people are spending excessive amounts of time using other technologies, too, such as social networking websites and hand-held texting devices.

Excessive use of technology can lead to both physical and mental health problems. People who sit in front of a computer monitor all day and night tend to be overweight and sleep deprived, have problems with their backs and vision, and may develop carpal tunnel syndrome. They may also have trouble setting and achieving goals, poor attention spans and social skills, and an inability to delay gratification.

The primary advantage of an inpatient program, says Cash, is that it allows people to completely cut ties with technology, a ubiquitous presence in modern society. Though patients will eventually have little choice but to use technology as part of their lives, a temporary fast, Cash says, can help them re-establish a bond with the off-line world. Some mental health experts, however, hesitate to recommend the cold-turkey approach.

"One thing that they try to do in these programs is completely cut access to electronic communication, but there is no evidence that going cold turkey is either advisable or good at effecting long-term success," says Dr. Elias Aboujaoude, director of the Impulse Control Disorders Clinic at the Stanford University School of Medicine in California.

Inpatient programs to treat Internet addiction are common in some countries, such as China and South Korea, but there is little scientific evidence to prove that they work. The success rates of such programs are often based on information supplied by the people who run them, which is not enough to justify their high costs, says Aboujaoude, who in 2006 led a telephone survey of 2513 adults to look for potential markers for problematic Internet use (CNS Spectr. 2006;11:750-5). For his patients, Aboujaoude usually recommends cognitive behavioural therapy as a first-line approach to treating Internet addiction.

"To be a productive, functioning human being, you need to have access to electronic communication," says Aboujaoude. "A better approach might 
be to gradually wean a person off and introduce new means of socializing and having fun."

Kimberly Young, director of an online resource called the Center for Internet Addiction, is not opposed to the idea of inpatient facilities but believes they aren't, in and of themselves, the solution. She notes that inpatient Internet addiction services have long been offered at many general addiction treatment centres including the Illinois Institute for Addiction Recovery in Peoria, Illinois, and Sierra Tucson in Tucson, Arizona. The problem is not a lack of facilities; rather, it's the lack of rapport between techsavvy patients and therapists who know nothing about Facebook or Twitter or World of Warcraft, she says.
"These places are around now and growing. The big issue isn't putting people in centres; it's training therapists how to assess and treat Internet addiction," adds Young, author of Caught in the Net.

Another criticism of programs designed exclusively for technology addicts is that they are too narrowly focused. Pathological use of computers, some mental experts say, is only a symptom of other problems, such as depression and social anxiety disorder.

"The fact that programs like these are focusing on this only is problematic in the sense that it doesn't treat all of the other issues," says Dr. Bruce Ballon, director of the Adolescent Clinical Education Service for Problem Gambling, Gaming and
Internet Use at the Centre for Addiction and Mental Health. "Our approach is to look at everything."

Cash doesn't deny that people who can't pull themselves away from a computer, even to save their jobs or relationships, have other issues. But those issues can't be effectively addressed, she says, if patients remain immersed in a virtual world.

Therapists who only talk to Internet addicts about depression or anger, and fail to address their technology fixation, will make little progress, says Cash. "You have to treat the addiction first, because the addiction is its own beast." — Roger Collier, CMAJ

DOI:10.1503/cmaj.109-3051 